\title{
Reply to Nel, Garrouste, and Schubnel (2019) "The wing venation of Odonata. International Journal of Odonatology"
}

\author{
John W.H. Trueman* and Richard J. Rowe \\ Research School of Biology, Australian National University, Canberra, Australia
}

(Received 3 May 2019; accepted 8 August 2019)

\begin{abstract}
We address six issues raised by Nel, Garrouste and Schubnel (2019) concerning the scheme of wing vein homology and nomenclature proposed by Trueman and Rowe (2019); showing in particular how evidence presented in a tomographical study of a dragonfly wing by Jacquelin et al. (2018) fits into this scheme.
\end{abstract}

Keywords: Odonatoidea; wing venation; homologies; dragonfly

Trueman and Rowe (2019) proposed a system of homologies and consequent wing vein nomenclature for the Odonata based on a re-examination of morphology and on current studies in evolution and development. Nel, Garrouste, and Schubnel (2019) raise six points against the Trueman and Rowe proposal, and argue for an amended version of the Riek and Kukalová-Peck system (originally proposed in Riek \& Kukalová-Peck, 1984). In our view the points raised by Nel, Garrouste and Schubnel do not amount to a refutation, and some of the evidence they draw on to support their position, from a paper by Jacquelin et al. (2018), in fact refutes their position. We address each of their points in turn.

Point one was that vein AA would "jump" in Mesozoic Isophlebiidae. The illustration used by Nel, Garrouste and Schubnel was of a fragment of the wing of Anisophlebia helle in which AA, terminating before the arculus, is separated from a more distal and caudal vein they label "AA?". We fully agree that the true AA is the vein labelled AA, but the identity of "AA?" is not obvious from this fragment. Its identity becomes clear if we take an isophlebiid species in which more of the wing is preserved. Figure 1 is a detail of the basal one-fourth of a wing of Bellabrunetia catherinae, redrawn from an illustration in Fleck and Nel (2002). The vein in contention is vein $\mathrm{Q}-\mathrm{R}$. It is apparent to us that $\mathrm{CuP}$ is joined to $\mathrm{Q}$ by a crossvein and that $\mathrm{Q}-\mathrm{R}$ represents the distal half of a supplementary vein, P-Q-R. In our terminology a supplementary is a secondary vein, typically of limited taxonomic distribution, formed by alignment of the crossveins between two rows of polygonal cells.

Point two was that our MA is in the nature of an intercalary vein, especially as to the manner in which it connects, at its base, with the adjacent veins. Nel, Garrouste and Schubnel use a figure of Thaumatoneura to illustrate their argument. To address this point it might be helpful first to consider the nature of intercalary veins. An intercalary is not a secondary alignment of

*Corresponding author. Email: truemanic@gmail.com 


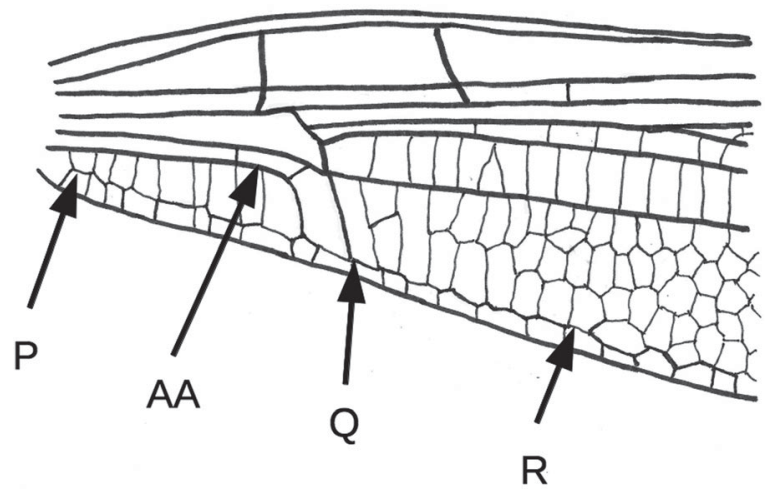

Figure 1. Detail of forewing of Bellabrunetia catherinae (Isophlebioptera, Campterophlebiidae). After Fleck and Nel (2002, figure 1A).

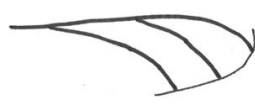

A

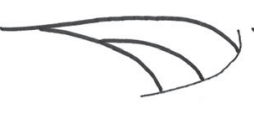

B

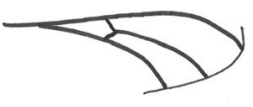

C

Figure 2. The three ways in which an intercalary vein may connect to the vein of opposite polarity of which it is a branch.

crossveins but is a branch of a vein on the opposite surface of the wing. To take the intercalary in the RP space as an example, vein IR1 is present in Odonata, in most or all Ephemeroptera and across a broad range of Neoptera. There are three venational patterns by which an intercalary can connect to adjacent main veins or to the two adjacent branches of the main vein, in this case RP, of which it forms part. Figure 2 shows these possibilities. All three occur in IR1 in extant insects. The nomenclatural difficulty is that although any pattern would support the nomenclature RP1, RP2, RP3, when the orientation is ignored pattern A can equally be read as RP1a, RP1b, RP2, pattern B can be RP1, RP2a, RP2b, and pattern C can be RP1, IR1, RP2. Our choice of label IR1 names this vein unequivocally and avoids the awkwardness of an upper-surface vein with what might be taken for a lower-surface name.

Vein MA in our system is formed in the same manner as vein IR1. The vein is present in almost every order, and all three patterns occur in Odonata. While Nel, Garrouste and Schubnel illustrate pattern C in Thaumatoneura they might equally have chosen, say, Cordulegaster. Most anisopterans show pattern A. Heterophlebia, an "anisozygopteran", shows pattern B. Most zygopterans show pattern $\mathrm{C}$ although in some families the connection is strongly asymmetric, the link to RP appearing far more like a crossvein than does the link to M.

We label this vein MA not IR3 for two reasons. (Note, in some nomenclatures it is IR2: the distinction hinges on whether it is the intercalary behind RP3 or the second of two intercalary veins.) First, in all other orders this vein is called MA. Second, it has been shown (in Drosophila) that the developmental boundary between epicoxal and subcoxal tissues runs immediately behind RP. Since this vein is situated behind the boundary it is formed from subcoxal not epicoxal material and it would be incorrect to name it as if it were an R-series vein. Any nerve chord in this vein must run from the medial basevenale, because innervation across the compartment boundary is not possible (see Trueman \& Rowe, 2019, pp. 80-81). The evolutionary histories of supplementary veins and intercalary veins suggest a supplementary vein is not likely to enclose a nerve chord, whereas a nerve chord is likely to be present in an intercalary. We have examined MA for the presence of movable setae, a clear indicator of innervation. The prediction, if this vein is an upper-surface branch of the lower-surface $M$ vein, is that setae would be present on the 


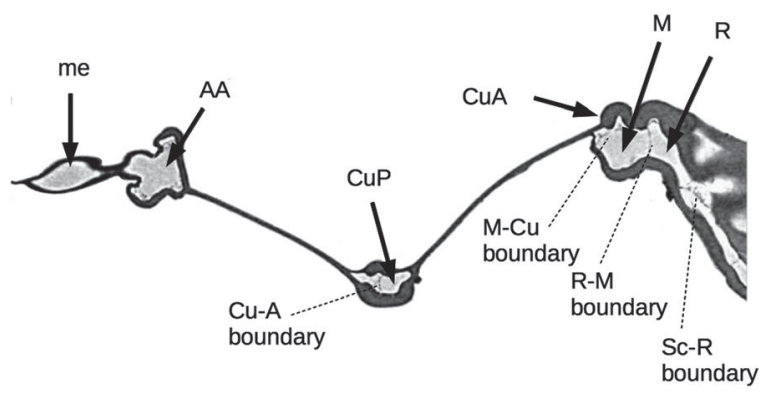

Figure 3. Detail of a section through the wing of Aeshna at the position of Ax0. Redrawn after Jacquelin et al. (2018, figure $2 \mathrm{C}$ ). Upper labels: the main veins from the trailing edge to the triple stem (me $=$ membranule). Lower labels: the septa between developmental compartments. The broad mass at the right is the posterior end of Ax0.

upper wing surface alone. Among Anisoptera, moveable setae occur on the upper side of this vein in all inspected representatives of families Petaluridae, Aeshnidae, Gomphidae, Austropetaliidae and Libellulidae. In Zygoptera, movable setae occur in Lestidae and Diphlebiidae but not in Synlestidae, Argiolestidae, Coenagrionidae and Isostictidae. Fixed cuticular spines occur on the lower surface in all families examined, with the exception of Isostictidae, but in no family are there any moveable setae on the lower surface. Thus, the vein is constructed as would be expected under our model. Given the phylogenetic tree of Dijkstra et al. (2013), we interpret the absences as a secondary loss. We consider this vein in Odonata to be homologous with vein MA of other insect orders.

Point three was that the first two components of what we have termed the triple stem, TS, emerge from the same bulla and must therefore be of the same series. Nel, Garrouste and Schubnel identify these veins as RA and RP, citing as relevant evidence the tomographic study of the wing base of Aeshna isosceles by Jacquelin et al. (2018). We thank Nel, Garrouste and Schubnel for bringing this paper to our attention, but in the matter of the triple stem it very neatly supports our hypothesis that these two veins are stem-R and stem-M and that the bulla is a concatenation of two axilliary structures as a result of wing-base narrowing in Odonatoidea.

Note first that figures 2C, D of Jacquelin et al. are upside-down, with CA mislabelled CP, $\mathrm{CP}$ mislabelled ScA, and ScA mislabelled CA. On our hypothesis, developmental compartmentalisation of the wing will be indicated by septa between adjacent compartments. These septa are clearly visible in Jacquelin et al.'s figure. The septum between ScP and the branch of ScA that forms part of $\mathrm{Ax} 0$ (the remainder appears, from this figure, to be of radial origin) has been labelled "limit ScP" by Jacquelin et al. A second septum, separating ScA from R, is labelled "limit R", and a third, separating R from M, is labelled "limit MA-R". A fourth such septum, not labelled and not mentioned by either Jacquelin et al. or by Nel, Garrouste and Schubnel, is situated towards the upper, rear surface of the vein complex that has been labelled MA.

In Figure 3 we redraw and relabel the rear half of Jacquelin et al.'s figure 2C, D, oriented with the dorsal surface on top and magnified so that the septa are visible. The main veins and compartment boundaries are labelled. Note that if this section had been taken anywhere but through Ax0 there would be no intervening branch of ScA in this figure. Instead, the R compartment would link to $\mathrm{ScP}$ by a transparent membrane, of R-compartment origin, extending as far forward as the septum identified by Jacquelin et al. as "limit ScP".

On Nel, Garrouste and Schubnel's hypothesis the septum labelled "M-Cu boundary" in our Figure 3 would not exist. On our hypothesis it separates the third component of the triple stem, $\mathrm{CuA}$, from the second component, stem-M.

Point four was that two veins are fused together at the base of CuP. There is, indeed, a septum, as shown in Jacquelin et al. (2018, figure 2C, D) (or see our Figure 3). It marks the boundary 
between subcoxal exite tissue (veins $\mathrm{M}$ and $\mathrm{Cu}$ ) and subcoxal endite tissue (veins $\mathrm{A}$ and $\mathrm{J}$ ). Its existence demonstrates that, at its base, $\mathrm{CuP}$ is not wholly formed on $\mathrm{Cu}$ compartment tissue but straddles the anal-field boundary. This explains the external morphology, which has misled several authors of odonate wing nomenclatures, including Riek and Kukalová-Peck, into thinking there is an additional longitudinal vein stem in this region. We observe that the nerve chord runs along the underside of the $\mathrm{Cu}$ section of this vein base and services a row of moveable setae on that surface only, so is of $\mathrm{Cu}$ origin.

The evidence for a small region of thick cuticle in the basal anterior corner of the anal compartment, adjacent to the base of $\mathrm{CuP}$, may help our understanding of how the subcoxal exite and endite lobes are fused. It would be interesting to see whether a homologue of this thickened area occurs in other orders.

Point five was that, contra Trueman and Rowe, vein ScA extends no further than crossvein Ax0. To us this proposition was surprising because ScA with its row of short, blunt setae extending at least to the wing tip, is so clearly visible to the naked eye. The evidence cited by Nel, Garrouste and Schubnel is that the 3D-CT scan reconstructions in Jacquelin et al. (2018) have ScA terminating at Ax0. However, Jacquelin et al. state unequivocally that this is not the case. While a basal, free segment of ScA (coloured red in their model) extends to Ax0, the vein itself continues, bound tightly alongside a vein they identify as CA. The segment of ScA beyond Ax0 is coloured deep blue in their model. Thus, Nel, Garrouste and Schubnel are mistaken; vein ScA continues well beyond Ax0. Because Jacquelin et al. (2018) have mislabelled CA for CP in their 3D reconstructions, the vein to which $\mathrm{ScA}$ is attached is $\mathrm{CP}$, not $\mathrm{CA}$. (For reference, the disposition of the three longitudinal components of the anterior spar, AS, have long been well-established: CA followed by CP followed by ScA. Figure 12B of Riek and Kukalová-Peck (1984) shows the arrangement.)

Point six was that, in Carboniferous Enigmaptera magnifica, the vein complex we refer to as TS is configured as two veins separated by a narrow membraneous field. Nel, Garrouste and Schubnel attempt an interpretation according to the Trueman and Rowe system but it is not the interpretation we would make. Unfortunately, the wing base is not preserved or else is hidden under matrix (see fig 2 of Nel, Roques, Prokop, \& Garrouste, 2018 refers) so all we have to go on is the venation as shown. The presence of RA, RP, and M in the outer wing would indicate that the first component already incorporates $\mathrm{R}$ with $\mathrm{M}$. The vein parallel with this vein is $\mathrm{CuA}$. The $\mathrm{Cu}$ field is broad at its base as in modern Odonata. One of the two crossveins labelled "??" in part A of the figure will be the homologue of the anal crossing, Ac, but a second such crossvein in the $\mathrm{Cu}$-AA space is not unknown even in extant species. The oblique crossvein that Nel, Garrouste and Schubnel label MP by their system and CuA by the Trueman and Rowe system is in the position of the crossvein that today runs from $\mathrm{CuA}$ to $\mathrm{CuP}$ within the sclerotised area at the base of the $\mathrm{Cu}$ space, meaning it is homologous also with the more longitudinally oriented crossvein that has formerly been mistaken for a supernumerary, truncated longitudinal vein in such fossil genera as Ditaxineura, Kennedya, and Epilestes. In Figure 4 we redraw the wing fragment shown in Nel, Garrouste and Schubnel's figure 3, labelling it as Trueman and Rowe (2019) would label it.

To conclude, all six problem venations put forward by Nel, Garrouste, and Schubnel (2019) fit cleanly into our proposed Trueman and Rowe nomenclatural scheme and none challenge it. The Riek and Kukalová-Peck system, being based on a mis-specified exite-lobe model for the origin of the wing, cannot be true. Wings are derived from exites and endites of the proto-insect leg, including from an epipodite that previously has been misinterpreted as of paranotal origin. Reiger, Shultz and Kambic (2005), and von Reumont et al. (2011) established the phylogenetic relationship of Insecta to Crustacea, while the work of Bruce and Patel (2018) confirmed multiple lines of evidence that the insect wing, together with the pleuron and sternum, evolved from pleurite lobes and the first two podomeres of the crustacean leg. The hinge joint arrangement 


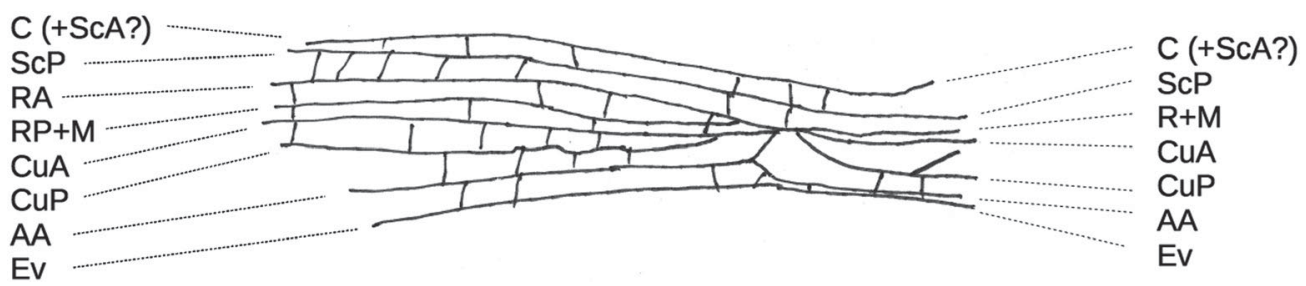

Figure 4. Fragment of venation of Enigmaptera magnifica, drawn after Nel et al. (2018) and Nel et al. (2019), labelled (contra Nel et al. 2019, figure 3A) according to the Trueman and Rowe system.

of insect wings matches these structures and their positions, so it is far more parsimonious to conclude that these are the same structures than to have them disappear and to evolve new ones de novo.

Garcia-Bellido, Ripoll and Morata (1973) demonstrated the developmental compartmentalisation that would be expected under this model, while Fristrom, Wilcox, and Fristrom (1993) and Kimura, Kodama, Hayasaka, \& Ohta (2004) elucidated the mechanism by which transparent wing membrane is produced; by a secondary process that truncates the secretion of cuticle and bonds the upper and lower cuticle of membranous areas back to back. The veins, with their fully developed cuticle, occur where this secondary process is not applied. The process is mediated by the presence of a ridge on one or the other epithelium. Each main longitudinal vein of the wing is, thus, inherently on either the upper or the lower wing surface, by virtue of the orientation of its ridge, regardless of the degree to which either epithelium produces a thick cuticle and whether that cuticle is sclerotised.

The "rules" for evolution of veins (see Trueman \& Rowe, 2019, pp. 80-81) follow from these mechanics of wing and vein formation. The resulting pattern is for eight pairs of veins, each with an anterior upper and a posterior lower branch. The first and fifth pairs, PC and M, may primitively be stemmed ( $\mathrm{PC}$ is usually suppressed, $\mathrm{M}$ is stemmed in all winged insects). The other pairs primitively are separated at their base but $\mathrm{R}$ is secondarily stemmed in some odonatoids. The basal sclerites are fused in Palaeoptera and especially so in Odonata, where the basal parts of the $\mathrm{R}-\mathrm{M}$ and $\mathrm{M}-\mathrm{Cu}$ membranous fields are completely suppressed, as is the C-Sc membranous field, and the cuticle of the CA-CP field is very thick. These modifications to the insect groundplan produce a triple stem at the base at midwing $(\mathrm{R}+\mathrm{M}+\mathrm{CuA})$ and a stiff spar $(\mathrm{CA}+\mathrm{CP}+\mathrm{ScA})$ along the leading edge. The Trueman and Rowe nomenclature follows directly from the system of inter-ordinal homologies that are implied by this model.

We believe that the Trueman and Rowe system provides a consistent terminology for the main veins of the dragonfly wing. The system is consistent with current views on deep insect evolution from a crustacean ancestor and consistent with a pleurite origin of wings from exite and endite precursors on leg segments that have become shortened and flattened to create the body wall. The system provides a very straightforward explanation of the evolutionary history of Odonata, consistent with the phylogenetics of the Order, and proposes homologies which align the wing-vein nomenclatures of all Pterygote wings.

\section{References}

Bruce, H. S., \& Patel, N. H. (2018). Insect wings and body wall evolved from ancient leg segments. bioR $\chi$ iv (BioRxiv), 244541. https://doi.org/10.1101/244541

Dijkstra, K.-D. B., Bechly, G., Bybee, S. M., Dow, R. A., Dumont, H. J., Fleck, G., Garrison, R. W., Hämäläinen, M., Kalkman, V. J., Karube, H., May, M. L., Orr, A. G., Paulson, D. R., Rehn, A. C., Theischinger, G., Trueman, J. W. H., van Tol, J., von Ellenrieder, N., \& Ware. J. (2013). The classification and diversity of dragonflies and damselflies (Odonata). Zootaxa, 3703(1), 36-45. 
Fleck, G., \& Nell, A. (2002). The first Isophlebioid dragonfly (Odonata: Isophlebioptera: Campterophlebiidae) from the Mesozoic of China. Palaeontology, 45(6), 1123-1136.

Fristrom, D., Wilcox, M., \& Fristrom, J. (1993). The distribution of PS integrins, laminin A and F-actin during key stages in Drosophila wing development. Development, 117, 509-523.

Garcia-Bellido, A., Ripoll, P., \& Morata, G. (1973). Developmental compartmentalisation of the wing disk of Drosophila. Nature New Biology, 245(147), 251-253.

Jacquelin, L., Desutter-Grandcolas, L., Chintauan-Marquier, I., Boistel, R., Zheng, D.-R., Prokop, J., \& Nel, A. (2018). New insights on basivenal sclerites using 3D tools and homology of wing veins in Odonatoptera (Insecta). Scientific Reports, 8(238), 1-7.

Kimura, K., Kodama, A., Hayasaka, Y., \& Ohta, T. (2004). Activation of the cAMP/PKA signaling pathway is required for post-ecdysial cell death in wing epidermal cells of Drosophila melanogaster. Development, 131, 1597-1606.

Nel, A., Garrouste, R., \& Schubnel, T. (2019). Response to Trueman and Rowe (2019) "The wing venation of Odonata. International Journal of Odonatology”. International Journal of Odonatology, 22(2), 115-119. doi: 10.1080/13887890.2019.1602085

Nel, A., Roques, P., Prokop, J., \& Garrouste, R. (2018). A new, extraordinary 'damselfly-like' Odonatoptera from the Pennsylvanian of the Avion locality in Pas-de-Calais, France (Insecta: 'Exopterygota'). Alcheringa, 43(2), 241-245. https://doi.org/10.1080/03115518.2018.1489561

Regier, J., Shultz, J., \& Kambic, R. (2005). Pancrustacean phylogeny: hexapods are terrestrial crustaceans and maxillopods are not monophyletic. Proceedings of the Royal Society of London B: Biological Sciences, 272(1561), 395-401.

Riek, E. F., \& Kukalová-Peck, J. (1984). A new interpretation of dragonfly wing venation based upon early Upper Carboniferous fossils from Argentina (Insecta: Odonatoidea) and basic character states in pterygote wings. Canadian Journal of Zoology, 62, 1150-1166.

Trueman, J. W. H., \& Rowe, R. J. (2019). The wing venation of Odonata. International Journal of Odonatology, 22(1), 73-88. https://doi.org/10.1080/13887890.2019.1570876

von Reumont, B., Jenner, R., Wills, M., Dell'Ampio, E., Pass, G., Ebersberger, I., Meyer, B., Koenemann, S., Iliffe, T., Stamatakis, A., Niehuis, O., Meusemann, K., \& Misof, B. (2011). Pancrustacean phylogeny in the light of new phylogenomic data: Support for Remipedia as the possible sister group of Hexapoda. Molecular Biology and Evolution, 29(3), 1031-1045. 